\title{
SECUENCIAS INFEROPALEOLÍTICAS EN LA CUENCA MEDIA DEL DUERO
}

\section{LOWER PALAEOLITHIC SEQUENCES IN THE DUERO MIDDLE BASIN}

\author{
por \\ JOSÉ-MANUEL BENITO ÁLVAREZ \\ LUIS BENITO DEL REY
}

RESUMEN Síntesis de posibles secuencias de terrazas fluviales pleistocénicas, en la cuenca del Duero, con industrias líticas datables en el Paleolítico Inferior.

ABSTRACT
with lithic industries dated from lower Paleolithic.

Palabras claves Pre-Achelense, Achelense, Paleolítico inferior, terrazas fluviales, cuenca del Duero.

Key words Pre-Acheulian, Acheulian, lower Paleolithic, fluvial terraces, Duero basin.

\section{INTRODUCCIÓN}

La investigación del Paleolítico Inferior en la Submeseta Norte puede parecer, a primera vista, envidiable por la entidad de los yacimientos excavados. En efecto, a lugares tan emblemáticos como Torralba y Ambrona, en Soria, y el complejo cárstico de Atapuerca, en Burgos, se unen otros de gran interés como San Quirce de Río Pisuerga, en Palencia, o La Maya y El Basalito, en Salamanca. Sin embargo, de momento, no ha sido posible establecer correspondencias cronoculturales entre ellos. A esto se une el desigual reparto de los esfuerzos investigadores, demasiado volcados hacia los lugares 'llamativos', dejando totalmente, de lado, la investigación de otros sitios, tal vez menos emblemáticos, pero, por esta situación, aquéllos aparecen rodeados casi de un desierto científico. Por otra parte, falta, además, la investigación básica, la que debería hacerse en los laboratorios, algo obligado en todas las áreas de Prehistoria y Arqueología de las Universidades. No hay que olvidar que, aquélla, inteligentemente estimulada, es el complemento para el desarrollo científico, 
y ayuda imprescindible para entender y ampliar el panorama de conocimientos ofrecido por los yacimientos 'noticia'. Las excavaciones y estudios de estos lugares tienen que servir de acicate para potenciar las demás investigaciones paleolíticas -de yacimientos y de base-. En este trabajo, hacemos una referencia especial a los de la cuenca del Duero, totalmente abandonados a su suerte en la actualidad.

Como muestra de lo que podría lograrse en el "desierto" de las investigaciones que rodean los yacimientos emblemáticos, ofrecemos una síntesis de las posibles secuencias culturales del Paleolítico Inferior de la cuenca central del Duero, aún en las primeras etapas de su estudio. Precisamente, una de las labores más interesantes del profesor Vallespí y su equipo fue el establecimiento de secuencias paleolíticas en el valle del Guadalquivir (por ejemplo, desde Díaz del Olmo, Vallespí y Álvarez 1987, hasta Díaz del Olmo, Vallespí y Baena 1993). Nos honramos, pues, en rendir homenaje, con este breve artículo, a su irremplazable labor científica.

\section{SECUENCIAS PALEOLÍTICAS EN LA CUENCA MEDIA DEL DUERO (fig. 1)}

Antes de comenzar, merece la pena repasar diferentes intentos de secuenciación, fuera o dentro del sector que hemos elegido para este estudio. Sin duda, la más sólida y completa de tales secuencias es la que ofrecen los yacimientos del complejo cárstico de Atapuerca, con la salvedad de que se compone de asentamientos en cueva, en tanto que las demás secuencias se basan -como nuestras propuestas- en sitios al aire libre y en terrazas fluviales. Forzosamente, éstos están peor conservados y son más problemáticos, pero, en contrapartida, están más diversificados y dan información más variada, aunque fragmentaria. Ignorarlos sería obviar una notable faceta de la ocupación humana, que podría contribuir a un mejor conocimiento de los yacimientos célebres, aunque sólo fuera por contraste.

\subsection{La secuencia del complejo cárstico de Atapuerca}

Es bastante difícil correlacionar los datos recogidos en los distintos yacimientos del complejo cárstico de Atapuerca, con otros procedentes de sitios al aire libre. Por eso, es de necesidad intensificar el estudio de estos últimos e intentar relacionarlos. Pues, hasta el momento, sólo Atapuerca-por falta de investigaciones en otros yacimientos-permite atestiguar, con solidez científica, la presencia humana a lo largo del Pleistoceno; y sólo Atapuerca la ha jalonado, al menos hasta ahora, de fechas absolutas, aunque la presencia humana esté, allí, poco desarrollada. Los lugares que nos interesan, puesto que estamos hablando de la evolución de las industrias, son los de la Trinchera, sobre todo Gran Dolina y Galería (Aguirre, Carbonell y Bermúdez de Castro 1987; Carbonell, Giralt y otros 1995; Bermúdez de Castro, Arsuaga, Carbonell y Rodríguez 1999: 192-205). En ellos se reconocen las siguientes fases:

2.1.1.- Modo técnico 1 o Pre-Achelense: documentado desde hace, al menos, un millón de años en el nivel TD4 y TD5 de Gran Dolina, aunque la serie más significativa corresponde a TD6, estrato con unos 800000 años, en el que aparecieron, también, los restos de Homo antecessor. Encontramos cantos tallados, núcleos desorganizados, denticulados y raederas.

2.1.2.- Modo técnico 2 o Achelense: Aparece, básicamente, en los niveles de Galería, con una antigüedad que oscila entre los 350.000 y 128.000 años. La mayor parte de las piezas corresponde a sucesivos niveles de ocupación, muy esporádicos, de TG10 y TG11, destacando los núcleos, mayoritariamente de extracciones organizadas (centrípetas y paralelas), bifaces, hendidores y triedros, así como raederas, puntas y denticulados. 


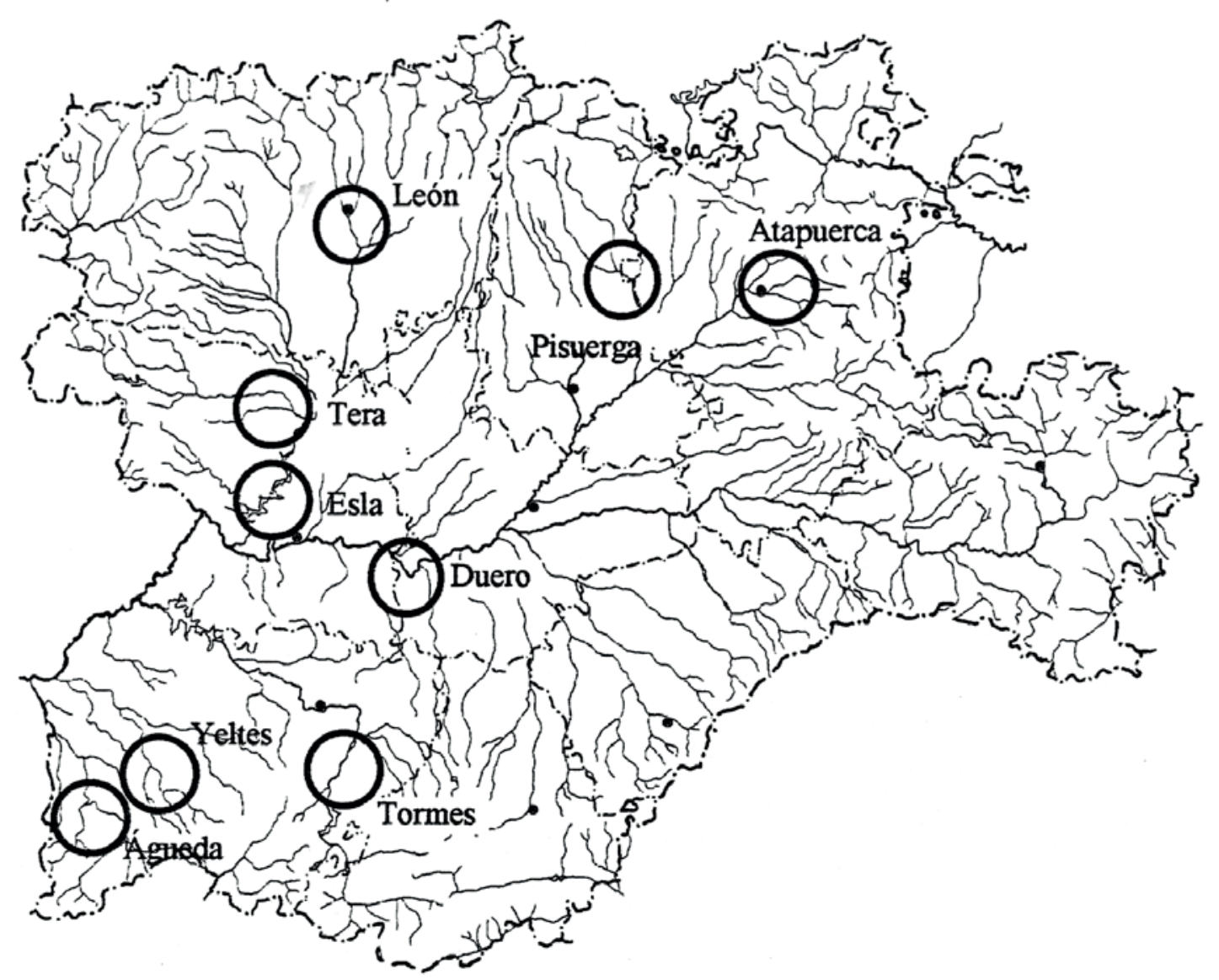

Fig. 1.- Localización de las secuencias citadas en el texto.

La hechura ${ }^{1}$ de los bifaces evoluciona hacia una morfología más alargada, con una talla cada vez "más flexible", según los citados autores. Culturalmente, partimos de una posición intermedia, dentro del Achelense, hasta llegar a un Achelense Superior, a techo de la secuencia.

2.1.3.- Modo técnico 3 o Musteriense Antiguo: de nuevo volvemos a Gran Dolina, a los niveles TD11 y TD12, que tienen hasta 300.000 años de antigüedad, caracterizados por la presencia de utensilios sobre lasca, de tamaño pequeño y mediano, y núcleos de extracciones centrípetas bastante estandarizados.

La gama crono-cultural se está completando aún, con hallazgos en la Sima del Elefante, tal vez más antiguos que los de Gran Dolina.

1. "La "hechura" es una parte de la talla (es la talla, sensu stricto, y su resultado), que consiste en desbastar un trozo de materia prima (guijarro, trozo de piedra, riñón de sílex, plaqueta e, incluso, una lasca) para darle la forma adecuada, que, salvo algunas excepciones, tiende a la simetría y, consiguiendo crear una zona funcional específica, transformarlo en útil. La finalidad de esta "hechura" no es el aprovechamiento de las lascas que se van desprendiendo, como subproductos, a medida que progresa la talla (pueden emplearse, no obstante, secundariamente), sino el útil que va quedando (útil nuclear, en general), que puede ser un bifaz, un hendidor, un triedro, un poliedro, un esferoide o una bola" (BENITO DEL REY y BENITO ÁLVAREZ 1998, II: 42). 


\subsection{La secuencia del valle del río Pisuerga}

En el río Pisuerga, se conocía, desde hace tiempo, un intento de secuenciación, con escasos pero alentadores resultados, en los alrededores de Valladolid (Rojo y Moreno 1979). Recientemente, el sistemático estudio realizado, en la provincia de Palencia, por Miguel Ángel Arnáiz Alonso, de la universidad de Burgos, ha deparado una importante serie de industrias, completada con un yacimiento excavado: el de San Quirce de Río Pisuerga (Arnáiz 1995):

2.2.1.- La etapa más antigua estaría representada por la muestra de Itero del Castillo, en la terraza a +105 metros sobre el Pisuerga, con rodamiento fluvial, pero sin conexión estratigráfica. Se trata, quizás, de un Pre-Achelense: sin bifaces, con muchos cantos tallados y escasos utensilios sobre lasca.

2.2.2.- La segunda fase la marcan las industrias de Naveros de Pisuerga II, en la terraza a +70 metros. Ahora ya aparecen algunos hendidores y bifaces, pero siguen predominando los cantos tallados. Los utensilios sobre lasca son, sobre todo, raederas y denticulados. Podríamos estar hablando de un Achelense antiguo.

2.2.3.- La tercera fase es la mejor representada y correspondería a la terraza a +40 metros, con diecisiete lugares prospectados, destacando el yacimiento excavado de Los Llanos, en San Quirce de Río Pisuerga (Palencia). Dado que lo que nos interesa es la visión global de la secuencia, no vamos a poder diagnosticar este interesante lugar (en el que, por otro lado, llama la atención la escasez de bifaces, sólo uno, y hendidores, dos, entre más de 20.000 piezas exhumadas). Los demás sitios se caracterizan por el hecho de que, aunque los cantos tallados siguen siendo abundantes, ya han pasado a un segundo plano frente a los bifaces. Sin duda, estamos ante un Achelense sensu lato.

2.2.4.- Se cerraría el ciclo con la colección recuperada en Villamayor de Treviño, sobre una terraza, de altura muy desigual, de un afluente del Pisuerga, el Odra. Aquí, los cantos tallados ya empiezan a escasear, siendo más rica la subpoblación de núcleos y, sobre todo, la de bifaces, en cuya hechura intervino, a veces, el percutor blando. A esto hay que añadir unos utensilios sobre lasca más variados y de mejor factura: raederas, denticulados, truncaduras, buriles... Se trata, probablemente, de un Achelense con industria algo más evolucionada que la que aparece en el punto anterior.

En todo este proceso nos encontramos técnicas de extracción desorganizadas y centrípetas, lascas heterogéneas, cortas y gruesas, y no se ha detectado el método Levallois, al menos el clásico, destinado a obtener una lasca preferencial por cada núcleo.

\subsection{La secuencia de los valles de los ríos leoneses}

De la provincia de León conocemos, para este periodo, un estudio sobre yacimientos asentados en las terrazas de los ríos Porma, Órbigo y Bernesga (Castellanos 1986). La serie de industrias de este último río permite elaborar la siguiente secuencia:

2.3.1.- En la Terraza a $\mathbf{+ 8 5 / 9 0}$ metros (T5) se sitúa el de "El Montico", con características arcaicas, ya que los cantos tallados son tan abundantes o más que los bifaces.

2.3.2.- En la Terraza a $\mathbf{+ 5 5 / 6 0}$ metros (T3) los yacimientos son menos relevantes, pero pertenecen a un Achelense típico, esta vez, en sentido amplio. 
2.3.3.- En la terraza a $+\mathbf{4 0}$ metros (T2) estarían La Luniega y Oteruelo. Sería Achelense, con los bifaces como los utensilios más representados.

A partir de ahí, se correlacionarían otros yacimientos: el de Villarrín del Páramo (valle del Órbigo) sería de edad similar a El Montico, mientras que Valdelamora (valle del Porma), sería similar a los de la Terraza T2, a +40 metros del Bernesga.

\subsection{La secuencia del valle del río Tormes}

Esta secuencia nace a raíz del descubrimiento del primer yacimiento de La Maya (Salamanca), en 1975, por el padre Belda, en compañía de uno de los firmantes de este artículo (Benito del Rey). Poco después, en asociación a dicho yacimiento se localizaron otros tres lugares secundarios con industria de superficie, con los que se confeccionó la siguiente progresión cronocultural (Santonja y Pérez-González 1984):

2.4.1.- Una primera fase formada por la minúscula y heterogénea colección de la terraza a +65 metros, en Gargabete y, sobre todo, por otras dos pequeñas series de sendas terrazas a +55 metros, en orillas opuestas del Tormes: La Maya-III. Se proponen fechas iniciales dentro del Achelense (Achelense A, según los citados investigadores).

2.4.2.- Una segunda fase está representada, en la terraza a +32 metros, en La Maya-II, y, a +20 metros, en La Azucarera de Salamanca. Estos lugares, y algún otro, ilustran el Achelense típico salmantino en sentido amplio (Achelense B, en la “innovadora” terminología de los citados investigadores ${ }^{2}$ ).

2. “Juzgamos de capital importancia para favorecer el progreso de la investigación, olvidar el modelo tripartito del Achelense, que parecía conferir a cada una de las etapas que distinguía entidad histórica real, como si, por ejemplo, Achelense medio fuera un concepto intercambiable con Imperio carolingio" (Santonja 1992: 38). Pide la anulación del concepto tripartito del Achelense, pero no ofrece nada constructivo y sustitutivo del cambio, sino el caos. La solución en definitiva es que, a partir de ahora, todos hablemos de Achelense A, Achelense B y Achelense, lo-que-sea. ¿Qué sugiere esta terminología? Nada. ¿Qué fronteras marca? Ninguna. ¿Por qué no puede surgir otro investigador que proponga, mañana mismo, otra clasificación? Y otra y otra. La ciencia exige respeto y seriedad, apreciaciones que brillan por su ausencia en la susodicha frase de Santonja. Aquel desbarajuste de términos nos obliga a salirle al paso para intentar poner un poco de orden en lo que él ha desordenado:

$1^{\circ}$.- Si no se conoce la cronía de un yacimiento achelense, hay que hablar de:

a) Achelense sensu lato, cuando tal yacimiento presenta los útiles propios o que caracterizan al Achelense: bifaces de estilo achelense, hendidores que presenten, mayoritariamente, un talón lateral, triedros, cantos tallados, núcleos de tipos diversos, lascas e industria sobre lasca.

b) Achelense arcaizante, si la técnica y la tipificación de los útiles presentan rasgos arcaicos.

c) Achelense evolucionado, si presenta unas técnicas de fabricación y una tipificación de los útiles evolucionadas, como es la presencia de tipos "evolucionados" entre los bifaces y, sobre todo, el uso predominante y generalizado del percutor blando en su fabricación.

$2^{\circ}$.- Por otro lado, cuando se conozca la cronía de un yacimiento, mientras no se den razones perentorias para el cambio de denominaciones, debe seguir hablándose de las divisiones clásicas (Achelense Antiguo o Inferior, Achelense Medio y Achelense Superior), y hacer las oportunas reflexiones, como se ha venido utilizando hasta ahora; pues, antes de cambiar esa terminología, si hubiera que hacerlo, hay que presentar razones de peso y pensárselo mucho o caeremos en un desbarajuste. Los cambios continuos en los nombres que va empleando Santonja no aportan más que embrollo al conocimiento del Achelense. Por eso, adelantaremos, ya, que lo que tiene que hacer, tal investigador, es aclararse, primero, él mismo, y, luego, proponer los cambios. Hay que tener en cuenta también que éstos, con todo lo razonables que pudieran parecer (lo que no quiere decir que lo sean), crearían una fractura entre la Prehistoria clásica y la posmoderna, haciéndola incomprensible. ¿Qué pasaría si el día de mañana se hicieran desaparecer, con lo que significan, las expresiones Historia Antigua, Historia Medieval, Historia Moderna e Historia Contemporánea? Pues, como cada edad tiene ya su concepto claro y preciso que entiende la gente, se originaría un auténtico galimatías de nombres. El 
2.4.3.- La última fase se situaría en las terrazas a +14 y +8 metros, en La Maya-I, cuya excavación proporcionó una industria de técnica achelense, aunque demasiado pobre en bifaces y cantos tallados, próxima al Pleistoceno Superior. Por ello, se propuso que ésta sería una industria derivada del Achelense regional, técnicamente más arcaizante, pero tipológicamente más innovadora.

COMENTARIO A LA SECUENCIA DEL VALLE DEL RÍO TORMES: Aunque se asegura que ésta es la secuencia más favorable de toda la Meseta Norte, por tamaño y posición estratigráfica (Santonja 1992: 36), a nosotros nos parece que la primera fase carece de consistencia ${ }^{3}$ y que la última ha sido interpretada de un modo demasiado confuso y titubeante. Sirva de ejemplo el baile de apelativos sobre su naturaleza cultural: en 1984, los niveles de La Maya-I fueron definidos como «Epi-Achelense Medio» $\mathrm{y}$ «Post-Achelense Superior» (Santonja y Pérez-González 1984: 304, 323, 336); en 1991, se colocaron en un supuesto y particular Paleolítico medio primitivo, aunque tuviera menos de 130000 años de antigüedad (Santonja 1991: 18 y 19), mientras que, poco después, sería Achelense superior (Santonja 1992: 30) ${ }^{4}$.

\subsection{La secuencia de los valles del Águeda y del Yeltes}

Se trata de afluentes del Duero, en el sudoeste de Salamanca, a los que habría que añadir el río Huebra (que no se ha incluido, al no ser posible la seriación de sus industrias ante la falta de un estudio geológico adecuado). La investigación de estos valles fue iniciada, lo que nos vemos obligados a revindicar, por uno de los firmantes de este artículo (Benito del Rey 1978) con la publicación de un yacimiento excepcional: "El Basalito", situado en el valle del Yeltes. Posteriormente, siguió el trabajo otro grupo de investigadores, sobre todo Martín Benito (2000). El resultado fue una serie de pequeñas colecciones, indudablemente seleccionadas, pero que son susceptibles de ser ordenadas $-\mathrm{y}$, consecuentemente, su significación perfeccionadaa partir de las terrazas fluviales.

mismo que está originando Santonja con el Paleolítico Inferior. Este problema de la terminología en el Paleolítico Inferior lo trataremos detenidamente en otra ocasión. Mientras tanto, Santonja debería reflexionar, con seriedad y criterios científicos, sobre el adagio latino que reza "non multa, sed multum", es decir, no conocer muchas cosas, sino saber mucho de las que se conocen, porque como explica y aclara hasta el más sencillo maestro de escuela, conocer no es saber. Santonja "conoce" muchas, muchísimas cosas, es verdad -aunque, quizás, fuera más exacto decir que tiene mucha información-, y así se lo reconocemos; pero en cuanto saber...lo que se dice "saber", deja mucho, muchísimo que desear. Cualquier observador honesto, perspicaz y científico puede comprobar lo que decimos en cualquier artículo o libro que tal autor haya publicado.

3. El conjunto de la industria de "La Maya III", localizado en una terraza alta del Tormes, y atribuido, por Santonja y Pérez González (1984: 319-321), al Achelense antiguo. Nosotros, que no hemos podido ver las piezas, dejamos expuestas nuestras reservas para dicha atribución:

$1^{\mathrm{a}}$.- La muestra es demasiado escasa para sacar ninguna conclusión, sobre todo, de tanta importancia (sólo se citan 15 piezas de superficie, entre las que nada más hay un fragmento de bifaz, y otras 20 en posición estratigráfica, aunque no in situ, en las que hay un solo bifaz.

2a.- "Además se recogieron tres núcleos Levallois de lascas..., que no se han tenido en cuenta en este estudio" (ibídem: 320), sinrazón que nos hace pensar que, por lo que fuera, no encajaban en su idea del resto de la de la colección, y los dejaron fuera, como si el yacimiento tuviera que estar de acuerdo con lo que piensa Santonja, y no al revés, como científicamente debe ser.

$3^{\mathrm{a}}$.- Citan también, los citados autores, "un núcleo protolevallois de puntas atípico" (ibídem: 320).

Comentario: Para nosotros, la presencia de estas piezas -y, en concreto, las relacionadas con el método Levallois-, no es propia de un Achelense antiguo. Con tal material, no es prudente ni razonable hablar de Achelense antiguo en el yacimiento de "La Maya III", como ya señalamos nosotros mismos en 1989 (BENITO DEL REY y BENITO ÁLVAREZ (1992): 137).

4. Es un auténtico baile de nombres. 


\subsubsection{Terrazas del río Águeda:}

En las terrazas del río Águeda, en los alrededores de Ciudad Rodrigo (Salamanca), nos encontramos con el siguiente proceso (los datos sobre técnica lítica proceden de Martín Benito 2000: 178 y 208, y de la investigación de uno de nosotros [J.-M. B.] sobre las muestras de alguno de los lugares citados; mientras que los de la geomorfología proceden de Martín Herrero y otros 1990: 42):

2.5.1.1.- TERRAZA A +60 metros (lugares con industria: Escobar del Palomar y Majuelos-Guadaña de Capilla): Nos basamos en la muestra más importante, la de Majuelos, que, no obstante, es pequeña. Además, no es seguro en qué tipo de depósito descansa, pues ninguna fuente geológica consultada identifica adecuadamente el coluvión cuaternario de este lugar. En esquema, sus características técnicas más importantes son que hay núcleos de extracciones centrípetas, pero no Levallois ni Kombewa. La hechura de los bifaces siempre se realizó con percutor duro, casi la mitad de ellos presenta las aristas rectificadas (también con percutor duro).

2.5.1.2.- TERRAZA A $\mathbf{+ 5 0}$ metros (lugares con industria: Teso de San Francisco [figura 2] y Rodillo de las Uvas): Son muestras un poco más significativas y se asientan con seguridad sobre restos de terrazas fluviales, aunque no hay piezas en estratigrafía. Junto a los núcleos de extracciones extensivas e intensivas

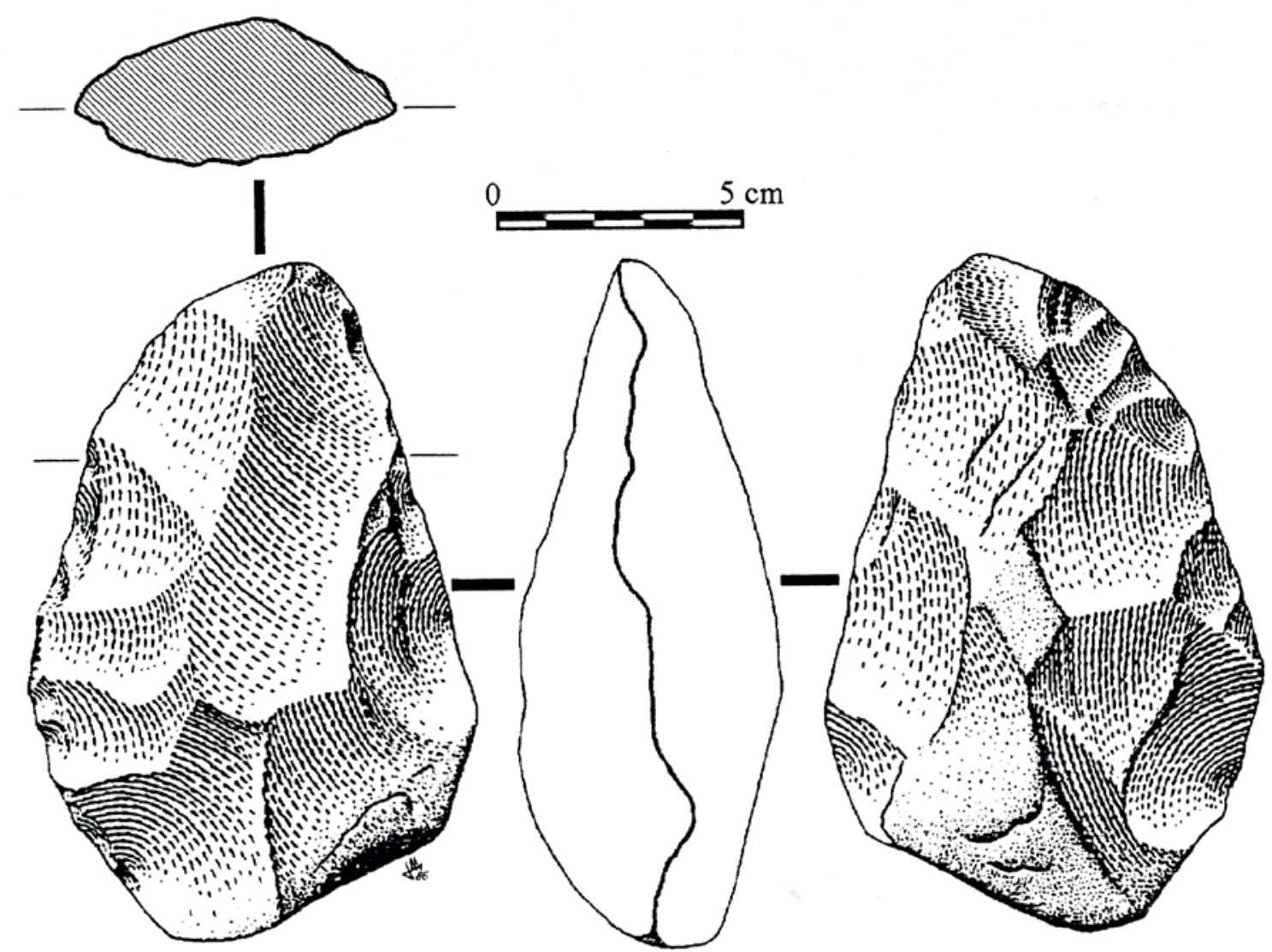

Fig. 2.- Bifaz amigdaloide, procedente de "El Teso de San Francisco" (Ciudad Rodrigo, Salamanca). 
desorganizadas y centrípetas, ya aparecen el método Kombewa y el Levallois, tanto preferencial como reiterativo. Los cantos tallados son, después de los bifaces, el tipo mejor representado. Los hendidores, como los triedros son pocos y muy sencillos, y los utensilios sobre lasca son escasos y toscos. La hechura de los bifaces se lleva a cabo, en la mayor parte de los casos, con percutor duro, con retalla rectificadora en más de la mitad de ellos. Ya hay bifaces total o parcialmente tallados con percutor blando.

2.5.1.3.- TERRAZA A $+\mathbf{4 0}$ metros (lugares con industria: Pedrotello y Cantarinillas): Series relativamente aceptables, sobre todo Cantarinillas, que tienen características equivalentes a las de la terraza inmediatamente anterior.

2.5.1.4.- TERRAZA A + $\mathbf{3 0}$ metros: Sólo se conoce una pequeña muestra muy poco significativa (Molino Carbonero), cuyos arcaizantes rasgos tecno-tipológicos son poco fiables.

Todas estas series están parcialmente sesgadas; no obstante, permiten apreciar la continuidad tecnotipológica y sitúan toda la secuencia en el Achelense, en sentido amplio. También se perciben ciertos cambios, sobre todo en las técnicas de lascado (aparición de métodos predeterminantes: Levallois y Kombewa...) y en la fabricación de los bifaces (hechura más cuidada, aparición del percutor blando...). Pero ignoramos si tales cambios responden a una auténtica evolución crono-cultural, a factores locales o a errores de muestreo.

\subsubsection{Terrazas del río Yeltes}

Por lo que respecta al vecino valle del Yeltes, la primera industria que se dio a conocer fue la del yacimiento de "El Basalito" (Benito del Rey 1978) en los alrededores de la localidad salmantina de Castraz de Yeltes 5 Unos años después, fue posible estudiar otras colecciones claramente más arcaizantes, pero sesgadas $-E l$ Lombo y Mesa Grande-, cuyo contraste técnico con las piezas de "El Basalito" era tan grande, que se llegó a proponer, para aquéllas, la pertenencia a un Achelense antiguo. Actualmente, el conocimiento del Achelense ibérico es más amplio y permite situar, en el Achelense, sin más, tales lugares. De este modo, la secuencia del río Yeltes continúa donde acaba la del Águeda, complementándola, especialmente, con la excavación arqueológica del yacimiento de "El Basalito". Podemos sintetizarla como sigue:

5. Este trabajo de BENITO DEL REY (1978), se ha calificado de "publicación ya trasnochada" (DIEZ MARTÍN 1999: 63). Al expresarse en tales términos, este último investigador está dando validez al "trasnochado" adagio, siempre vigente, de que "la ignorancia es atrevida". Porque, si hay algo objetivo y perenne en una publicación científica sobre industria de piedra en el Paleolítico es el estudio técnico de esa industria, que es la base-la base, repetimos-de todo estudio posterior y que no cambiará nunca-nunca, repetimos-por mucho que cambien "las modas" de los estudios sobre el Paleolítico. En efecto, nuestra publicación está sostenida, mayoritariamente, en tal estudio, con el que hay que contar siempre que se estudie esa industria. Si a ello le añadimos el control riguroso, minucioso y preciso de los dibujos que adjuntamos, se concluye que nuestra publicación sobre El Basalito es siempre -siempre, repetimos- válida, que puede y debe servir de soporte a otros estudios sobre el yacimiento; así que, de publicación "trasnochada", nada de nada. Las interpretaciones, como las que aplica el señor F. Díez Martín, son, a lo más, "modas", que, como tales, suelen cambiar; a veces, incluso, no tienen consistencia alguna y son, simplemente, "flor de un día". Además, tales "modas" han sido expuestas a veces, como en el trabajo de tal "investigador", sin el control icónico suficiente, necesario, demostrativo y fedatario, lo que obliga a acudir, para creerse lo que dice, a un "acto de fe". Y no debe olvidarse que la 'modernidad' en la investigación, -que pregona, para sus estudios, F. Díez Martín-, al calificar nuestro artículo de "trasnochado", no es, de por sí, criterio científico; es decir, que no es de recibo aceptar, científicamente, que estudios posteriores, por el mero hecho de ser posteriores, sean mejores que otro anterior. Por último, el propio autor dice, refiriéndose a nuestra publicación de "El Basalito", que "la muestra analizada es profundamente parcial y aleatoria. Prueba de ello es que el exiguo conjunto (60 piezas) adolece de la más mínima sistemática prospectora (Díez Martín 1999: 63, nota 4), cuando la realidad es que la colección consta de 63 piezas. La consecuencia, elemental, que se saca de ello, es que tal autor osa hacer una crítica científica, cuando todavía no sabe contar ni sumar. Apodíctico. 
2.5.2.1.- TERRAZA A +35/40 metros, con los sitios de El Lombo y Mesa Grande, cuyos rasgos son propios del Achelense, equivalente al de terrazas a la misma altura relativa en el Águeda. El tipo lítico más representado es el bifaz (aunque su abundancia, proporcionalmente, se deba, quizá, a las condiciones del muestreo). Fabricado sobre guijarro, es grueso y de silueta oval o amigdaloide; sus aristas fueron talladas con percutor duro y, a menudo, rectificadas por medio de una retalla, también con percutor duro. Aunque está presente, raramente se utilizó el percutor blando). Le siguen en importancia los cantos tallados y los núcleos. Éstos indican una relativa diversificación: de extracciones desorganizadas, centrípetas, Kombewa, Levallois... Las lascas más comunes son semicorticales, anchas y de talón cortical. Son raros los utensilios sobre lasca; también son escasos los hendidores (generalmente, de tipos sencillos), lo mismo que los triedros ${ }^{6}$.

\section{El Basalito es para la industria lítica, lo que Atapuerca es para los restos humanos: son dos yacimien- tos paleolíticos complementarios.}

2.5.2.2.- TerrazA A +14 metros: con el yacimiento de "El Basalito", excavado por nosotros en 1987, que deparó una industria que podría suponer el colofón de esta secuencia por sus rasgos evolucionados. Se distinguieron hasta cinco niveles arqueológicos, aunque aquí hablaremos sólo del nivel III, que, en general, sintetiza, los rasgos esenciales del Achelense de "El Basalito".

El 95\% de las piezas exhumadas son lascas, de las que sólo una quinta parte fue transformada en útiles. Las lascas más abundantes son las vulgares, seguidas de los subproductos de la hechura de bifaces con percutor blando, es decir, lascas-desecho resultantes de tallar y retallar bifaces con percutores de hasta, madera dura o hueso, e incluso piedra blanda, y, en algún caso, posiblemente también para rectificar y afilar sus aristas después de su utilización.

- En general, las simples lascas denotan técnicas de extracción muy variadas (extensivas, intensivas, paralelas, centrípetas, Levallois, Kombewa...).

- Entre los útiles sobre lasca, destacan las raederas (alguna bellamente rematada con percutor blando), los denticulados, las muescas, así como utensilios indeterminados. Aunque no por su número, son muy interesantes los buriles.

- Le siguen en importancia los núcleos, la mayoría, pequeños, toscos y de extracciones desorganizadas, a lo sumo groseramente centrípetas.

- Los cantos tallados no son muy numerosos.

- Los bifaces del nivel estudiado son los más numerosos y son piezas a menudo bellísimas, excepcionalmente acabadas con percutor blando. Aparte que la morfología de sus siluetas sea diversa y evolucionada (amigdaloides, ovales, lanceolados, cordiformes e, incluso, alguna micoquiense), cabe destacar la separación de dos grupos de bifaces, (hecho que ya fue señalado, por primera vez, por uno de nosotros hace tiempo (Benito del Rey 1978: 75 y 79): existe, por un lado, un grupo de bifaces de morfología almendrada, alargados y de tamaño grande (en torno a los $12 \mathrm{~cm}$ de longitud, aunque alguno pueda llegar a casi $30 \mathrm{~cm}$ ), fabricados en cuarcita, con una excepcional hechura en la que ha intervenido intensamente el percutor blando, que ha conseguido unos bifaces de belleza sin par. Por otro lado, tenemos bifaces de morfología más irregular, almendrados o nucleiformes, de pequeño tamaño (en torno a $7 \mathrm{~cm}$ de longitud), fabricados

6. Los niveles fluviales en los que fue recogida la industria de estos dos lugares no son, evidentemente, los mismos ni más bajos que el que corresponde al excepcional yacimiento de "El Basalito". A pesar de que se haya afirmado, errónea y tendenciosamente, que "Cerca de El Basalito, en posición topográfica equivalente-aunque aún sin definir con exactitud-, o en cota topográfica ligeramente inferior, se sitúan El Lombo y Mesa Grande” (Santonja 1992: 35). En primer lugar, sí que está definido con exactitud, al menos para quien se molesta en visitar aquellos lugares con intenciones científicamente objetivas; $y$, en segundo lugar, la cota de estos dos últimos yacimientos no sólo no es inferior a la de "El Basalito", ni siquiera equivalente, sino que, contrariamente a lo que afirma Santonja, es una terraza claramente superior (más alta) y más antigua. 

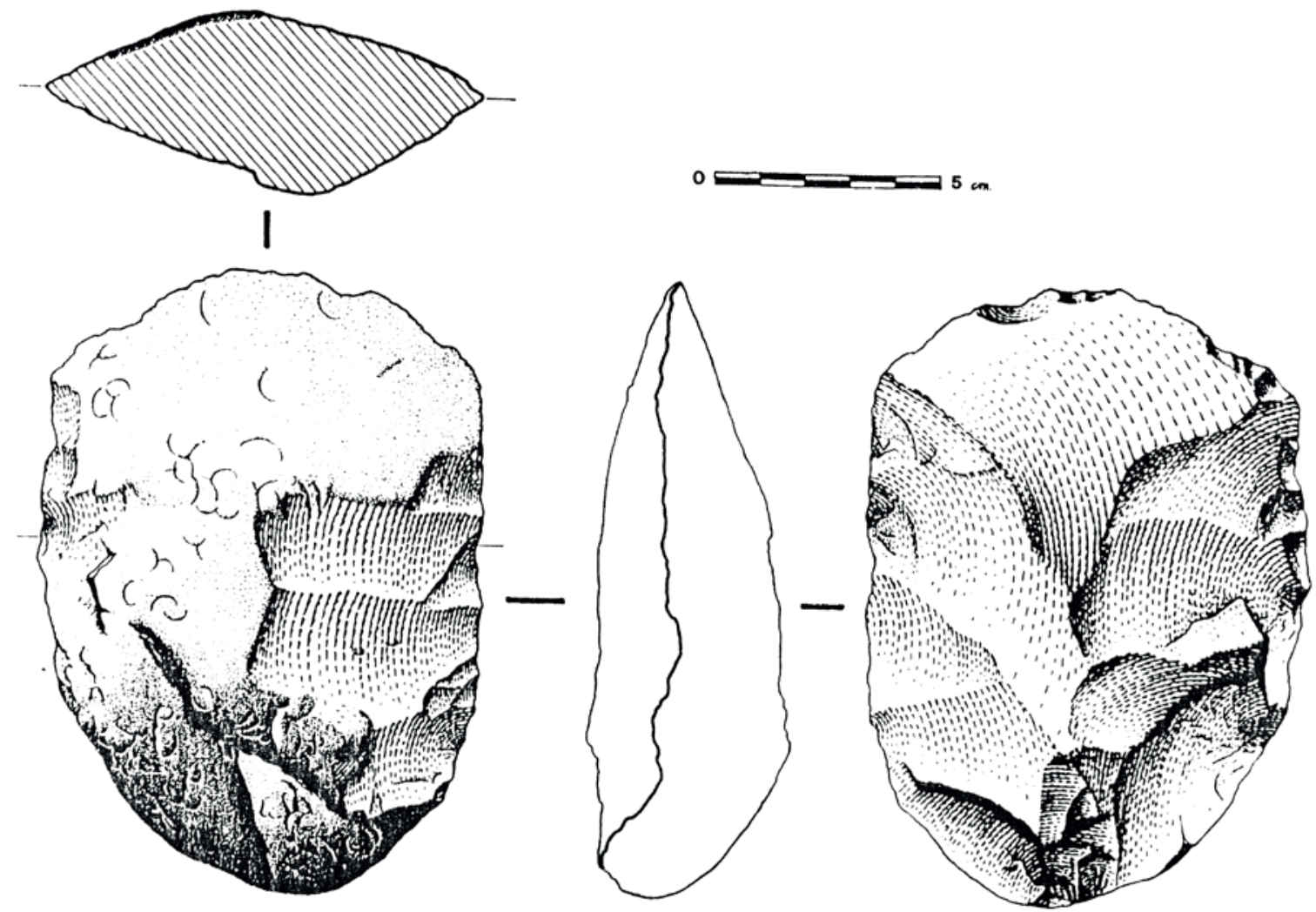

Fig. 3.- Espléndido hendidor de tipo 0, retocado con percutor blando. Yacimiento: El Basalito (Castraz de Yeltes, Salamanca).

sobre cuarcita o cuarzo, fundamentalmente, con percutor duro, aunque en alguno también intervino el percutor blando. La presencia de estos dos tipos de bifaces está siendo investigada, y ya sabemos que no responde a una mezcla, sino a particularidades específicas de la cadena operativa, según se explicará oportunamente $^{7}$.

- No hay triedros en El Basalito, pero sí hendidores: aunque escasos, son interesantes; uno de ellos está finamente retocado con percutor blando (figura 3).

7. Respecto a la errónea comprensión de lo que puede llegar a significar el entendimiento de estos dos tipos de bifaces, podemos recordar a Santonja, quien afirma que "series como El Basalito (Benito 1977) unen bifaces de tipología evolucionada que con arreglo a una concepción clásica no habría dificultad en definir como Achelense superior, con otros tallados con percutor duro exclusivamente, que aislados de los anteriores no desentonarían en cualquier conjunto achelense de las terrazas medias" (Santonja 1991-92: 35), afirmación que es, no sólo sesgada, sino completamente falsa, porque, en la colección estudiada, no hay bifaces que desentonen de los demás. Todo lo contrario: todos los bifaces estudiados presentan una hechura fresca, formando parte del mismo conjunto y entonando perfectamente dentro de él, con todas las demás características exactas que se explican en la publicación. Sr. Santonja: no es extraño que alguien como usted, que no tiene claros conocimientos de las características técnicas y tipológicas de los bifaces, llegue a ver mezclas de bifaces donde no las hay, como es la de una secuencia en la que su composición técnica y tipológica los integra perfectamente. Porque lo que hay que respetar es el yacimiento, no las teorías apriorísticas que uno tenga. Por lo tanto, no es postura científica despreciar o desacreditar yacimientos porque no encajen en las propias teorías. Los antiguos dieron, a este proceder, un nombre: 'lecho de Procusto'. El resultado de estas osadías-la ignorancia es muy atrevida-es un "totum revolutum" de las ideas y materiales que maneja Santonja, que siempre habrá algún incauto que se lo crea. 
En general, hemos interpretado este yacimiento como típicamente Achelense ${ }^{8}$. En él, la pericia que demuestra el artesano que elaboró sus bifaces (y alguna otra pieza) es tal, que da la impresión de que se deleitase en su hechura perfecta. La variedad de tipos (figura 4), junto a la alta calidad de la hechura de la mayoría de los bifaces, induciría a inclinarse, sin pensar, en un momento avanzado del Achelense. Pero, realmente, carecemos de fechas u otros indicios que permitan situar, con exactitud, la cronía ${ }^{9}$ de esa industria; por eso, en el estado actual de nuestros conocimientos y pensando, no se puede hablar de Achelense superior, que implica cronía; en consecuencia, como no podemos asegurar la edad de El Basalito, pero sí su alto grado de eficacia y desarrollo técnico, optamos por denominarlo "Achelense evolucionado", lo que es incuestionable, sin menoscabo, claro está, de que, en el futuro, pueda precisarse su edad, en cuyo caso ya podríamos hablar (pero sólo entonces) con conocimiento de causa, probablemente, de Achelense superior. En el estado actual de nuestros conocimientos, repetimos, esta atribución que, sin más, le dan algunos, no tiene más fundamento que el tipológico ${ }^{10}$.

De este modo, podemos concluir que la secuencia elaborada combinando datos de los valles del río Yeltes y del río Águeda en Salamanca, aún teniendo importantes puntos débiles -básicamente, la calidad de las muestras de superficie-, es muy útil, pues ofrece un panorama amplio y variado, susceptible de convertirse en una hipótesis sobre la que trabajar en el futuro: la innegable continuidad técnica coexiste con una evolución cierta, que pudiera responder a una diferente cronía real.

\subsection{La secuencia del valle del Duero entre Tordesillas y Toro}

El corto trecho en el que el Duero discurre entre Tordesillas (Valladolid) y Toro (Zamora) se sitúa a unos 650 metros sobre el nivel del mar. Es una zona de suaves campiñas formadas por materiales blandos del Terciario sobre los que se han formando una serie de terrazas, cuyo estudio ha servido de base a nuestro trabajo (Jiménez y García 1981, quienes las enumeran con una notación del tipo $\mathrm{Q}_{1} \mathrm{~T}_{4}$; Pérez-González [1982], en cambio, las denomina, por ejemplo, TD7). Gracias a ellos, estamos en condiciones de dar a conocer una serie de industrias que -a falta de datos más sólidos que lo confirmen-podrían abarcar, desde los primeros momentos de la ocupación humana de la zona, hasta fases avanzadas del Achelense. Estas industrias, no

8. Ya lo habíamos dicho nosotros, anteriormente, bien claro "El yacimiento de "El Basalito" es, rotundamente, un Achelense evolucionado" (BENITO DEL REY y BENITO ÁLVAREZ (1992): 165), conclusión a la que llegamos después de explicar una serie de razones que allí exponemos. Pero si es que, en este caso concreto, no hace falta exponer razones: nada más ver-decimos bien: "ver", no mirar-la industria lítica, que está compuesta, en su mayor y mejor parte, por bifaces, el más torpe de los aficionados sabe que es, si cabe, el yacimiento más achelense de los achelenses; y, sin duda, el mejor de la Submeseta Superior en industrias líticas. Por eso, sorprende más el hecho tendencioso de que SANTONJA GÓMEZ (1991: 19) diga, con relación a la industria paleolítica de "El Basalito", que "no hay que descartar que cuando se conozcan series representativas con suficiente utillaje sobre lasca y productos de talla, las industrias del Yeltes referidas ("El Basalito") pudieran encuadrarse en el Paleolítico medio". Lo que dice, Sr. Santonja, no es otra cosa que suposiciones, lo que le lleva a "disentir por el mero hecho de disentir" de lo que está suficientemente demostrado; pero el hecho de "disentir", señor Santonja, no es tener razón, si no se aportan los correspondientes justificantes, que, en forma de razones o pruebas, debe presentar quien disiente. Y, aquí, señor Santonja, una vez más, ni aporta usted razones ni prueba alguna, ni, por consiguiente, tiene razón.

9. Del griego $\chi \rho o ́ v o \varsigma=$ tiempo. El término "cronía" es, en determinados casos, más preciso que el término "cronología" (del

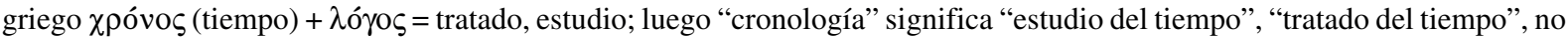
"el tiempo" per se que es lo que significa "cronía".

10. Lo que cualquiera sabe que es cuestionable, porque la Tipología no data, per se, las industrias, hecho que estamos cansados de repetir, desde hace muchos años, a nuestros alumnos universitarios. Lo que pasa, es que, a veces, es el único medio que tenemos de estudiar las industrias, porque no hay otros modos de hacerlo. El caso de "El Basalito" es diferente, porque sabemos, ciertamente, que su industria es evolucionada. Esa evolución responde a una tecnotipología, pero ignoramos, al menos en el estado actual de nuestros conocimientos, si se corresponde también con una cronía. 
obstante, plantean algunos dilemas derivados del hecho de que todas ellas están al aire libre, y, aunque en muchos casos se han localizado artefactos englobados en la estratificación fluvial, en el estado actual de nuestros conocimientos no existe certeza de la edad que tienen. Para ordenarlas, hemos elegido, como criterio principal, el agrupamiento geográfico. Así, tenemos, en el término municipal de Nava del Rey (Valladolid), las terrazas más altas y las fases más antiguas; en el de Pollos (Valladolid), una serie de terrazas medias-altas con un típico Achelense medio de la zona, y, en el de Toro (Zamora), las terrazas medias-bajas con las industrias más recientes:

2.6.1.- Zona de Nava del Rey (Valladolid): Se trata de una zona de altas terrazas, datadas, al menos, en el final del Pleistoceno inferior o en el principio del Pleistoceno medio. Aparte las colecciones que se van a citar, en la terraza a +114 metros de altura sobre el Duero $\left(\mathrm{TD} 3\right.$ o $\mathrm{Q}_{1} \mathrm{~T}_{2}$ ), se recogió una pequeña serie de piezas, apenas un puñado: cantos tallados, núcleos y alguna lasca. Estamos hablando del pago llamado La Taza (Nava del Rey), del que apenas hemos podido hacer averiguaciones. De momento, no hay datos para fechar esta escasa industria. Los restantes sitios son:

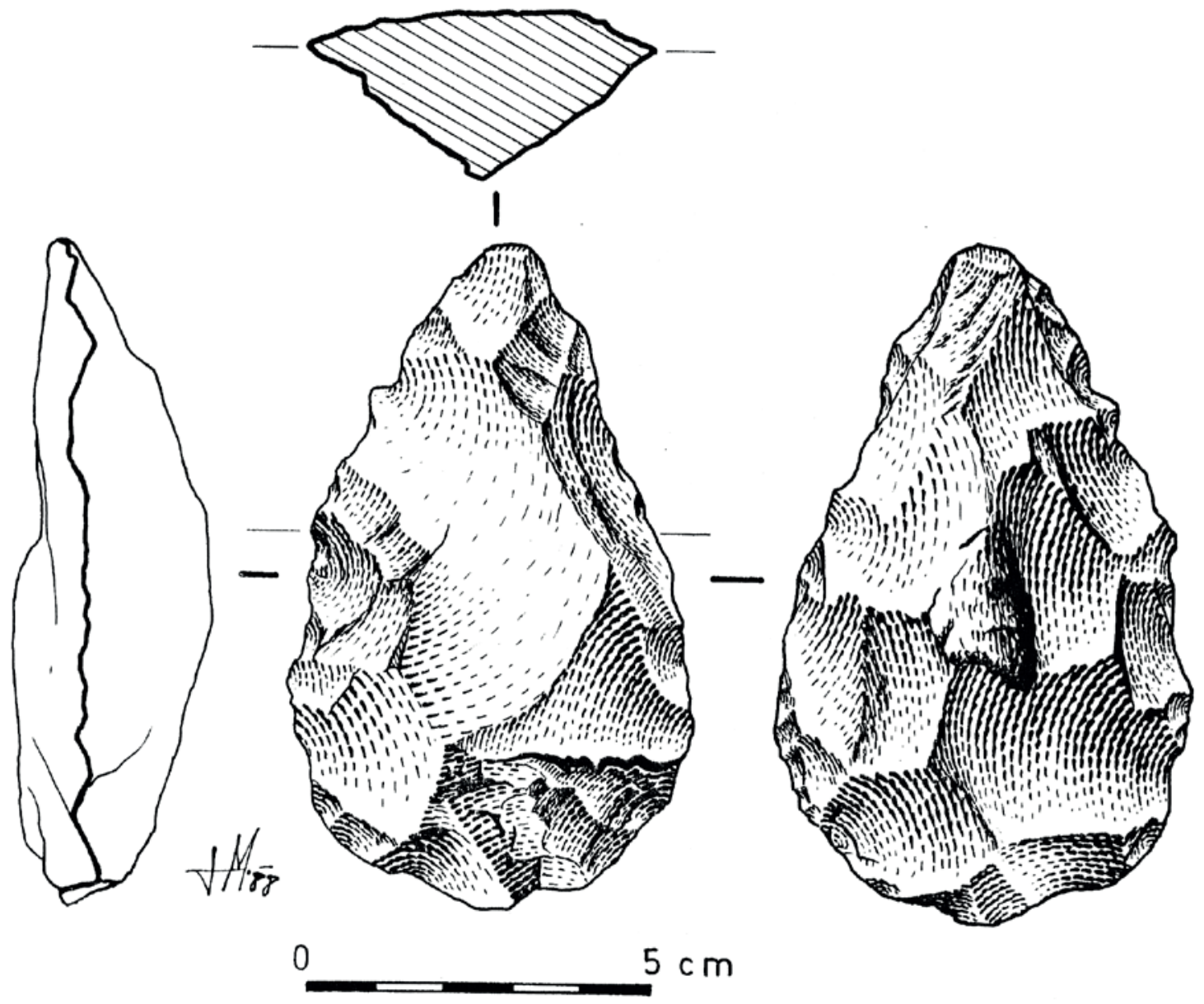

Fig. 4.- Bifaz amigdaloide alargado. Yacimiento: El Basalito (Castraz de Yeltes, Salamanca). 
2.6.1.1.- La Castella: a + $\mathbf{1 0 1}$ metros sobre el Duero (se trata de TD 5 o $\mathrm{Q}_{1} \mathrm{~T}_{4}$ a $+95 / 100$ metros): hablamos de casi un centenar de piezas, mayoritariamente cantos tallados y núcleos. Éstos son, sobre todo, núcleos de talla desorganizada, pero hay también bastantes con extracciones centrípetas. Igualmente, se han localizado ocho piezas en un perfil estratigráfico: una raedera y un denticulado, además de lascas y cantos tallados con concreciones calcáreas; no obstante, el depósito no ha podido ser estudiado todavía con detenimiento y no podemos asegurar que sea un nivel fluvial. Hay también bifaces, aunque escasos.

2.6.1.2.- El Pesebrón: a +90 metros sobre el Duero (que sería TD 6 o $\mathrm{Q}_{1} \mathrm{~T}_{4}$ a +85/90 metros): Aunque se recogieron varios centenares de piezas con rodamiento fluvial, no hay ninguna en estratigrafía. Es una industria prácticamente idéntica a la de La Castella, en la que dominan los cantos tallados (figura 5). Hay también bastantes núcleos, sobre todo con extracciones desorganizadas; igualmente, hay núcleos con lascados centrípetos y otros con extracciones paralelas, pero ninguno Levallois. Se reconocen algunas raederas, muescas y denticulados, siendo los bifaces, tallados siempre con percutor duro, particularmente escasos.

2.6.1.3.- Barco Rodrigo: a +77 metros sobre el Duero (TD 7 o $\mathrm{Q}_{1} \mathrm{~T}_{5}$ a $+75 / 80$ metros): De nuevo, una colección de varios centenares de piezas, muy similar a la anterior: muchos cantos tallados, seguidos de los núcleos, que son, sobre todo, de talla desorganizada. También aparecen los de extracciones centrípetas y los de lascados paralelos; pero la novedad son los grandes núcleos de extracciones extensivas. Los utensilios sobre lasca son escasos, destacando muescas y denticulados. Los bifaces, tallados siempre con percutor duro, siguen siendo pocos, pero abundan algo más que en el yacimiento anterior, y ya los hay con retalla rectificadora, realizada con el mismo tipo de percutor.

2.6.1.4.- El Cascón, a +66 metros (TD 8 a + 60/65 metros): La colección consta de casi cuatrocientas piezas, todas con rodamiento fluvial, pero sin asociación estratigráfica. Los cantos tallados siguen siendo los más abundantes, seguidos de los núcleos. Pero, aquí, los lascados centrípetos son sensiblemente más numerosos, y, lo que es más revelador, hay núcleos Levallois y un bifaz sobre lasca Kombewa (figura 6). Aunque el resto de los útiles escasea, su tipificación es muy variada: bifaces -algunos con retalla rectificadora, siempre con percutor duro-, triedros, hendidores, raederas, muescas, denticulados, etc.

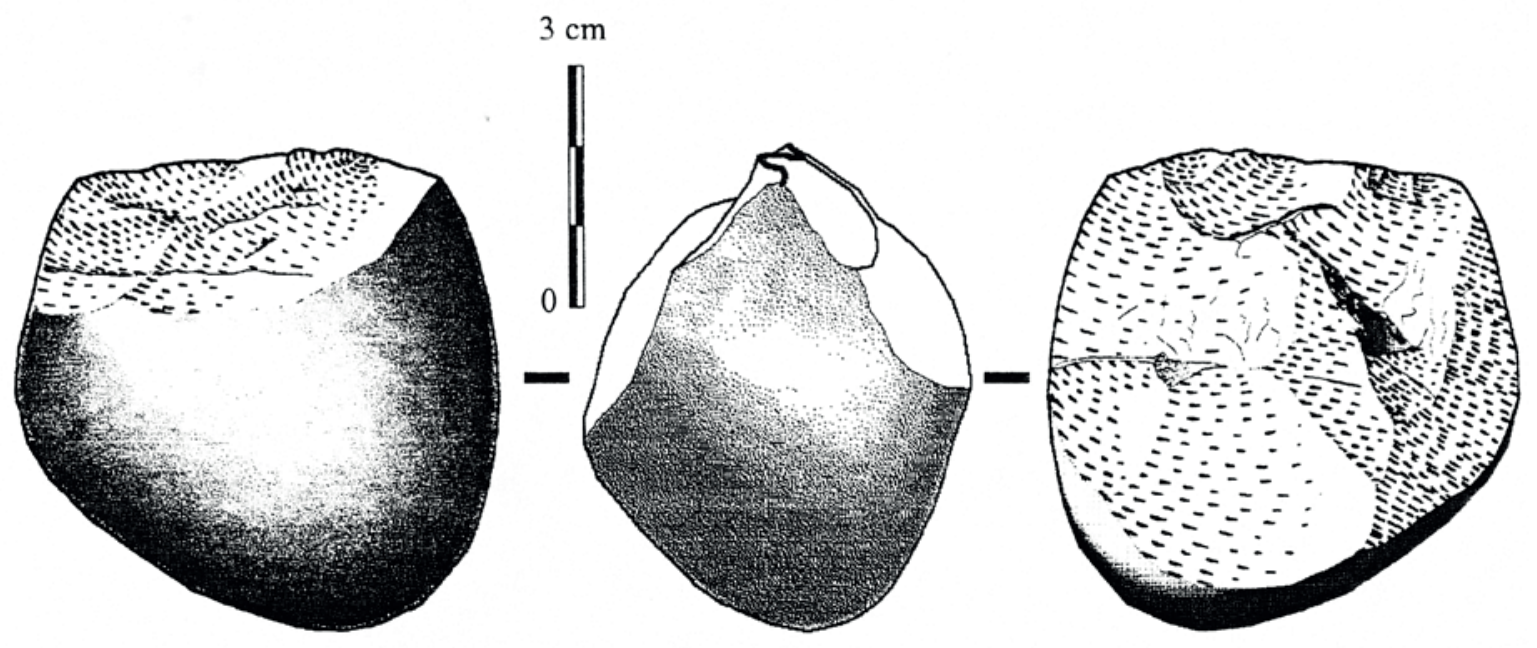

Fig. 5.- Canto tallado bifacial procedente del pago de "El Pesebrón" (Nava del Rey, Valladolid). 


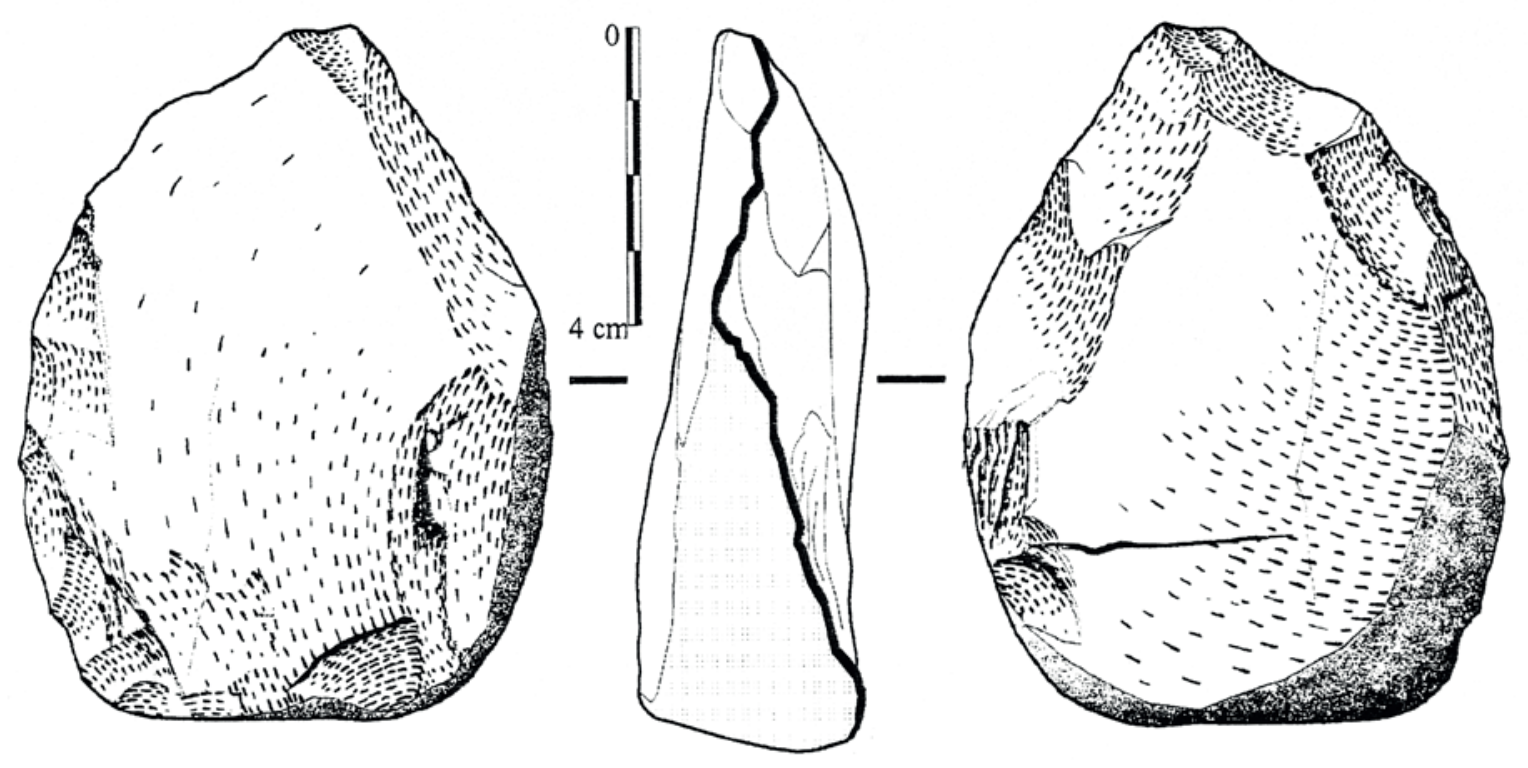

Fig. 6.- Bifaz sobre lasca Kombewa, tallado con percutor duro. Pago: El Cascón (Nava del Rey, Valladolid).

COMENTARIO A LAS INDUSTRIAS DE NAVA DEL REY: En general, debemos valorar esta serie de industrias con enorme cautela, dado que no hay ninguna seguridad de que su posición actual en las terrazas sea adecuada. Con todo, teniendo en cuenta el fuerte arcaísmo observado en estas industrias, parece correcto plantear la hipótesis de un Pre-Achelense o, al menos, un Achelense arcaico. Para confirmarlo, sería necesario localizar más piezas en posición estratigráfica. Por lo que respecta al sitio de El Cascón, el último de los tratados, la presencia de los métodos Levallois y Kombewa (figura 6) obliga a situar la industria dentro del Achelense medio, en sentido amplio.

2.6.2. Zona de Pollos (Valladolid): Las terrazas de esta zona ocupan grandes superficies fácilmente rastreables, ya que su aprovechamiento agrícola suele ser de secano, o de las excelentes viñas de la denominación de origen "Rueda".

2.6.2.1.- La Toribia: a $+\mathbf{5 4}$ metros sobre el Duero $\left(\mathrm{Q}_{1} \mathrm{~T}_{6} \mathrm{o} \mathrm{TD} 9 \mathrm{a}+50 / 55\right.$ metros $)$ : Éste es el primer sitio claramente asociado a la estratigrafía fluvial, pues se han localizado varias piezas talladas en el corte de una gravera (figura 7). En la serie, recogida en superficie, siguen predominando los cantos tallados, pero menos que en las colecciones de terrazas superiores. El porcentaje de núcleos de extracciones organizadas centrípetas aumenta, aunque siguen dominando los de talla desorganizada. De nuevo, aparecen núcleos Levallois. Los bifaces también son algo más numerosos y más cuidados, a veces con rectificación, y ya aparece, aunque raramente, el percutor blando en su hechura. Se completa la panoplia con algunos hendidores y triedros, raederas, muescas y denticulados.

2.6.2.2.- Cantosal-Buenavista (Foncastín, Valladolid): $\mathbf{a}+\mathbf{4 3}$ metros sobre el Duero (TD $10 \circ \mathrm{Q}_{1} \mathrm{~T}_{7} \mathrm{a}+$ 40/45 metros): La colección es, en casi todos los aspectos, similar a la de La Toribia, pero con cambios sutiles y reveladores: aunque sigan todavía, en porcentaje, por detrás de los cantos tallados, hay ya más bifaces y están más cuidados, con retalla-y, consiguientemente, con los bordes rectificados-en más ocasiones. 


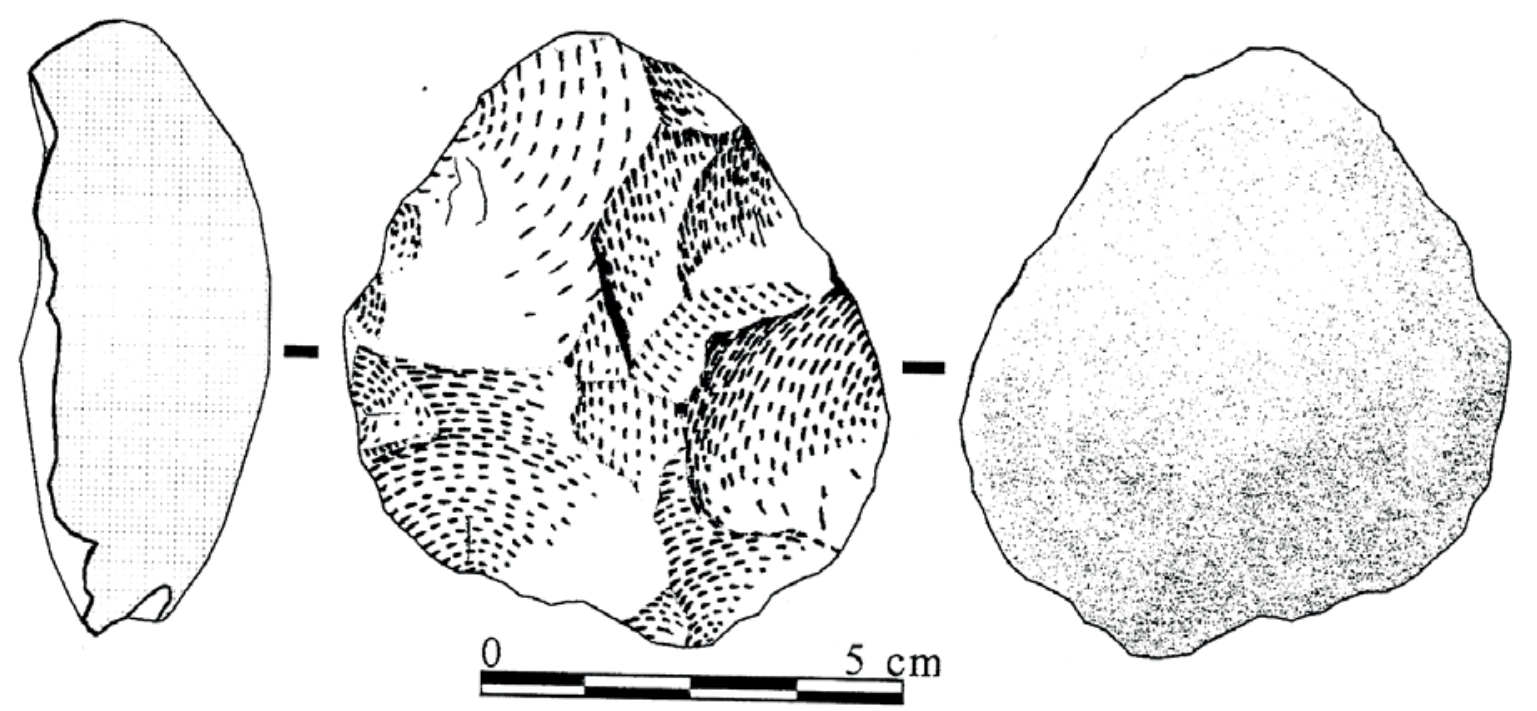

Fig. 7.- Núcleo Levallois de extracciones reiterativas. Es una de las piezas procedentes del interior de los estratos fluviales del pago de La Toribia (Pollos, Valladolid).

También se ha usado, más a menudo, el percutor blando. Otro cambio interesante, con relación al yacimiento anterior, es un aumento importante de la proporción de triedros, que sólo son superados por bifaces y cantos tallados. Ignoramos si esto responde a una dinámica evolutiva o no, pero no desentonan, en cuanto a su talla y demás características. de los que encontramos en terrazas más altas y más bajas.

COMENTARIO ALAS INDUSTRIAS DELAZONA DE POLLOS: Estos dos lugares, que son, excepto en las singularidades señaladas, muy parecidos, deben ser considerados dentro del Achelense medio sensu lato.

2.6.3.- Zona de Toro (Zamora ${ }^{11}$ : se trata de niveles de terraza más potentes y mejor conservados que en los casos anteriores. Pero también más difíciles de explorar, pues están muy aprovechados económicamente (urbanizaciones, graveras, regadíos...).

11. Debemos puntualizar lo siguiente con respecto a un supuesto "yacimiento" del valle del Valderaduey (Zamora):

$1^{\circ}$.- En 1984, Santonja dice, en relación a un "yacimiento" que lleva el nombre del pueblo de Monfarracinos situado en el susodicho valle, que "entre la grava amontonada en la superficie de la cantera... se recogió algo de industria" (Santonja y Pérez González 1984: 33). Ese "algo de industria" consiste en una probable lasca, porque las otras piezas que cita, son piezas sobre canto con algunos "levantamientos" sueltos, anómalos y muy problemáticos. Nosotros nos preguntamos si tales "levantamientos" no son otra cosa que simples roturas propias de algunos guijarros de terraza, que no tienen nada que ver con la intencionalidad humana. Además, estas piezas tan problemáticas, deberían tener, al publicarlas, al menos el control del dibujo, para que pudiéramos juzgar con cierta objetividad la supuesta "industria", cosa que no aparece por ninguna parte, por lo que se ve uno obligado a un "acto de fe" para creer que las piezas citadas tengan intervención humana.

$2^{\circ}$.- En 1986, los firmantes de este trabajo y J.I. Martín Benito, refiriéndonos al "yacimiento" de Monfarracinos, escribimos que "tales 'industrias' no pueden ser consideradas del Achelense-ausencia de útiles directores-, ni tan siquiera yacimiento, como pretenciosamente se ha escrito. Consideradas, como tal, a un simple-demasiado simple-hallazgo de meras lascas (únicamente, una sola probable) en un montón de grava" no es de recibo, no estando siquiera, tal probable lasca, en estratigrafía (Benito, Martín y Benito 1986: 12, nota 8). 
2.6.3.1.- Valdelama (Toro): a +35 metros sobre el Duero (que sería $\mathrm{Q}_{1} \mathrm{~T}_{8} \mathrm{o}$ TD 11 a +28/35 metros): El pago es una gravera en explotación, en cuyos niveles se encuentran numerosas piezas, incluso a varios metros de profundidad. Por primera vez estamos ante una serie con pocos cantos tallados; los núcleos son de tipos variados. Los bifaces, en cambio, parecen más arcaizantes que en colecciones supuestamente más antiguas (menos rectificación y menos percutor blando), mientras que, siguiendo las pautas de la colección de Cantosal, los triedros han aumentando su proporción hasta situarse a la altura de los bifaces. Los demás tipos están presentes, pero en menor cuantía (hendidores, raederas, muescas, denticulados...). Aunque estamos convencidos de que el Achelense de Valdelama no corresponde a momentos iniciales, sino, más bien, de mediados de la fase cultural. La abundancia de triedros nos induce a asociar esta industria con la de Pinedo, aparecida en los niveles fluviales de la terraza cuya base está a +22 metros y el techo a $+30 \mathrm{~m}$ sobre el río Tajo.

2.6.3.2.- Vega Grande (Castronuño, Valladolid): a +16 metros sobre el Duero (TD 12 o $Q_{1} T_{9}$ a + 15/20 metros): Colección numerosa, con artefactos en los depósitos de la terraza, localizados en un desmonte de la carretera, a pocos metros de donde se recogió la industria. Escasean los cantos tallados y los núcleos parecen estar determinados por la materia prima, que aquí aparece en guijarros mucho más grandes que en otras terrazas. Así, los núcleos de extracciones extensivas son numerosísimos, dando lugar a grandes lascas, a menudo predeterminadas, que sirven para fabricar bifaces y, sobre todo, hendidores. Éstos últimos venían siendo escasos hasta ahora, pero en esta terraza su proporción se dispara. Aquí sí que se ve la relación y, sobre todo, dependencia de la industria con relación al tipo y, sobre todo, tamaño de la materia prima: allí donde no hay materia prima de tamaño adecuado, no pueden sacar lascas apropiadas para la fabricación de hendidores. La abundancia de hendidores es fundamentalmente, pues, la novedad a destacar en Vega Grande (figura 8).

Aunque hemos encontrado industrias en niveles más bajos, en lo que hemos observado carecen de entidad $\mathrm{y}$, aparentemente al menos, son de características triviales.

COMENTARIOS SOBRE LA ZONA DE TORO: De momento, los niveles descritos en las terrazas de la zona de Toro son los más recientes; pero no indican cambios radicales en técnica o en tipificación. Más bien, domina la continuidad, salvo las innovaciones descritas en cada caso, que se van acumulando a medida que descendemos hacia el cauce del Duero. Da la impresión de que los hombres del Paleolítico Inferior estuvieran "atados" a la materia prima-soporte y a las técnicas tradicionales, y no tuviesen necesidad de grandes transformaciones en sus útiles para cubrir sus necesidades. Por eso, se observan pocas diferencias, en innovaciones técnicas, en la secuencia, aunque sí en la diferente presencia y proporción de la tipificación de útiles.

$3^{\circ}$.- En 1992, Santonja, refiriéndose a nuestra nota de 1986: 12, nota 8, dice: "La industria del Paleolítico inferior en posición estratigráfica ofrece siempre interés aunque se trate de piezas aisladas" (Santonja 1992: 16, nota 3), en lo que estamos totalmente de acuerdo. Pero no es aquí el caso, porque esa "industria" de que tratamos, se limita a una probable lasca, y a unos cantos con alguna extracción totalmente indeterminada y muy problemática, recogidos, no en estratigrafía, sino "entre la grava amontonada en la superficie de la cantera", como afirmaron, en su momento, Santonja y Pérez González (1984: 33) desconociendo, por tanto, su procedencia estratigráfica. Y sigue Santonja: "La significación (de esa probable lasca-y poco más o, quizás, menos-) es aún mayor cuando el hallazgo permite situar, como en este caso, los primeros indicios de presencia humana en la región" (Santonja, ibídem). Esto es, a nuestro parecer, lo verdaderamente grave: el hecho de que base, tal investigador, algo tan importante como es la constatación de la presencia humana, por primera vez, en la región, en algo tan débil, tan sin fundamento, como es el hallazgo, de una probable y sola lasca, recogida, además, en un montón de grava. 


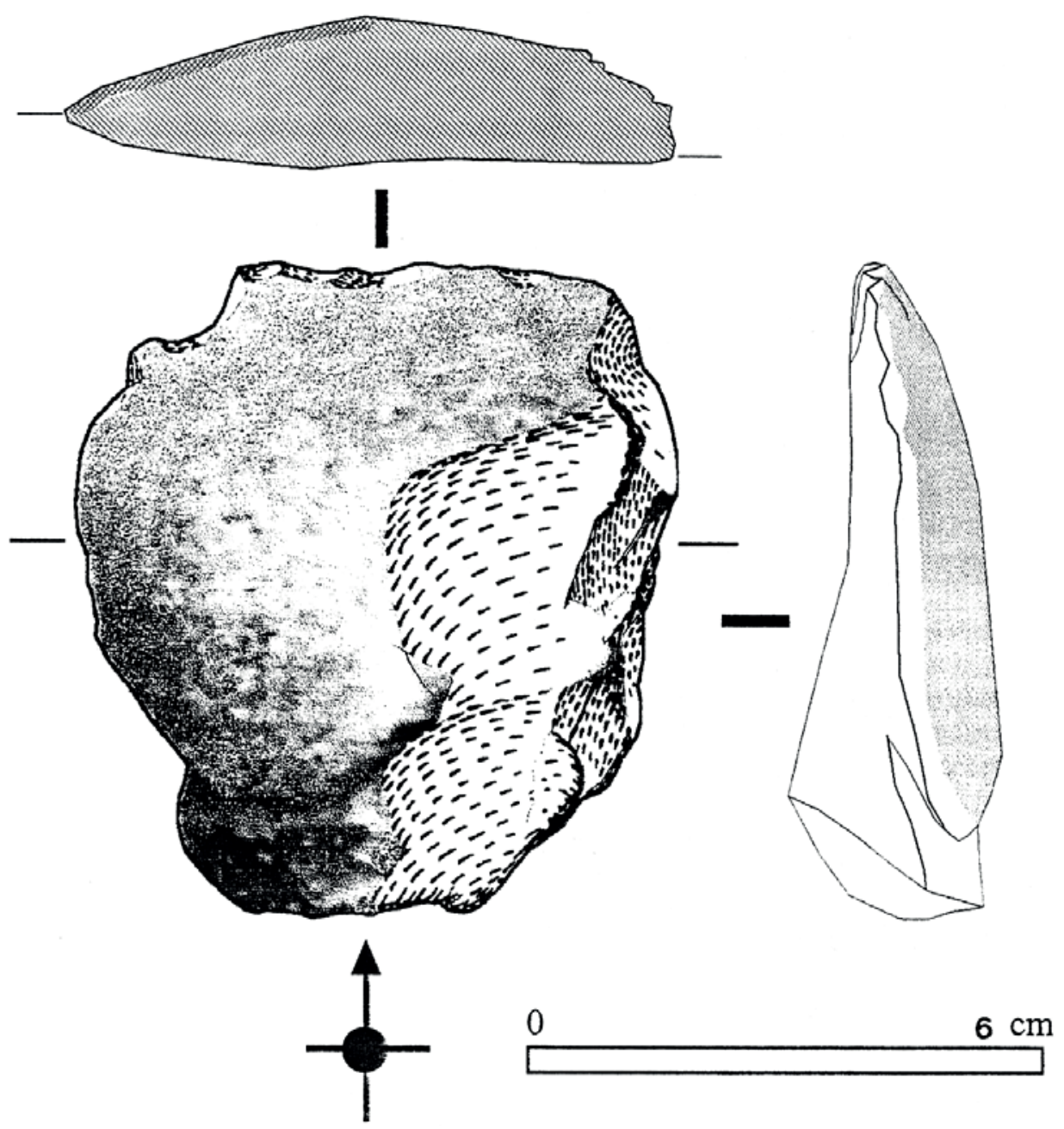

Fig. 8.- Hendidor de tipo 0, procedente del pago de Vega Grande (Castronuño, Valladolid).

COMENTARIO A LA SECUENCIA ESTUDIADA DEL VALLE DEL DUERO: Resumiendo lo anterior, referente al cauce del Duero entre Tordesillas (Valladolid) y Toro (Zamora) ${ }^{12}$, podemos decir que:

12. El estudio del resto de la provincia de Zamora con industrias paleolíticas conocidas $-\mathbf{y}$, sobre todo, las zonas de las terrazas del Esla y del Tera, que estábamos analizando y queríamos haber incluido en este trabajo-, no ha podido terminarse porque el agua caída en este invierno tan lluvioso (diciembre de 2000 y enero y febrero de 2001) tenía invadida la zona de algunos yacimientos y no se han podido recorrer adecuadamente. Su examen se terminará en una oportunidad climática más propicia. Con todo, diremos que, en el informe que presentó uno de nosotros (L.B.) en el I Congreso de Historia de Zamora, celebrado en 1988, se tuvo en cuenta, para la atribución de las industrias paleolíticas, la información de las terrazas en las que estaban. No se hizo referencia a ello, debido a que, como se afirma en nuestro propio trabajo, aunque sí había expuesto su estudio y conclusiones, en la comunicación pública a dicho congreso, "nuestro colega y amigo, el Profesor Santos Francés, quien se encargó del estudio de la Geología cuaternaria de la provincia de Zamora, ha declinado, al menos por ahora, publicar sus resultados" (BENITO DEL REY 1990: 11 nota con asterisco). Como es fácil comprender, y no le íbamos a masacrar su investigación, aprovechando y publicando una parte de su 
- Los cantos tallados aparecen en todos los niveles, pero su proporción va siendo más reducida a medida que bajamos hacia el cauce: dejan de ser los más numerosos a +43 metros y, al final, son ciertamente escasos.

- Los núcleos apenas fluctúan, salvo que aumentan, poco a poco, los de extracciones centrípetas y aparecen los núcleos de extracciones extensivas (a +77 metros).

- Los métodos Levallois y Kombewa se encuentran a partir de +66 metros y son proporcionalmente escasos, pero ya no dejan de estar presentes.

- La presencia de bifaces, que al principio es casi inexistente, aumenta poco a poco. A este incremento, le acompañan mejoras en su hechura (aparece la rectificación de aristas en +77 metros y el percutor blando desde +54 metros) y se convierten en el tipo más importante, proporcionalmente, desde las terrazas a +35 metros.

- Los triedros tienen un pequeño aumento proporcional, en torno a $+30 / 40$ metros, mientras que los hendidores sólo son relativamente abundantes al final (en +16 metros); ignoramos si esto se debe a la evolución cronológica en la tipificación de los útiles, pero lo que es innegable es que su fabricación está condicionada al tamaño de la materia prima.

\section{DISCUSIÓN GENERAL}

La objeción más importante, no sólo en el caso de nuestras secuencias, sino también en las demás, es que-a excepción de la del complejo cárstico de Atapuerca-, ninguna está hecha con datos de excavación, con todo lo que esto significa. A lo sumo, alguna de las fases representadas es un yacimiento excavado, pero nada más. Lógicamente, los datos de superficie son muy endebles, por más que se acompañen, a veces, de un puñado de piezas recogidas en la estratigrafía de perfiles y desmontes cercanos de la propia terraza. Lo cierto es que, ni en esos casos, tenemos la misma certeza que en una excavación, porque ignoramos si las piezas de superficie y las recogidas en la pared del estrato, que suelen ser pocas, son contemporáneas.

Teniendo siempre in mente que podemos estar viendo un espejismo, hemos de añadir que, al cotejar estas secuencias, a menudo elaboradas y estudiadas por especialistas muy diferentes en muchos aspectos, vemos más puntos en común que discrepancias. Nos encontramos con industrias de apariencia muy arcaica-sabemos por la Gran Dolina que hay industrias muy antiguas, y quizás correspondan a éstas en su cronía-, que dan paso a un Achelense con muchos cantos tallados, en el que los bifaces van aumentando su proporción y mejorando su hechura, al tiempo que perfeccionan el control de las técnicas de lascado. Poco más podemos decir en un artículo de estas dimensiones, ya que los demás utensilios requieren análisis más detallados para determinar en qué consiste su evolución. Además, al ser yacimientos de terraza, muchas veces los útiles pequeños o de menos peso fueron arrastrados y dispersos por el agua del río en sus avenidas, que sólo o mayormente depositaba los más grandes y pesados en determinados lugares, porque su corriente no podía arrastrarlos, y, si había depositado algunos, serían sometidos a arrastres de riadas y otros fenómenos posteriores, lo que acentuaría la dispersión, sobre todo de lascas y útiles sobre lasca, por ser los materiales menos pesados, algo para cuyo conocimiento no se necesita siquiera saber de Prehistoria, sino tener sentido común. Por ello, es más sorprendente que Santonja atribuya, a un defecto nuestro, el hecho de que, determinados yacimientos que publicamos situados en terrazas, tengan una proporción pequeña de lascas y de útiles sobre lasca, lo cual es normal y está en consonancia de lo que explicamos anteriormente. Consecuentemente,

estudio, pues no es ésa la ética científica. Por eso, resulta más sorprendente, tendencioso y parcial, el hecho de que Santonja (1992: 35) afirme que nosotros hemos atribuido nuestras industrias, basados exclusivamente en criterios tecnotipológicos, sacando así, él, las cosas de su contexto y haciendo un totum revolutum de lo que dicen cuatro o cinco investigadores. El investigador que carece de precisión y objetividad en sus publicaciones, no es científico: un paradigma de ello es, entre otros muchos, que, en el trabajo citado de Santonja de 1992, en una sola página -por ejemplo, la 15-, tal investigador hace cinco citas bibliográficas, encabezadas por Martín Benito; pues bien, las cinco están equivocadas. Et ita porro. 
las lascas y útiles sobre lasca que se recogen, no se corresponden con las que hubo en el yacimiento originario, en el que, tales piezas, debieron estar representadas en una proporción mucho mayor ${ }^{13}$.

Lo que sí es innegable, es que no tenemos aún suficientes datos estratigráficos, ni siquiera contando con los de Atapuerca, para establecer un modelo cronológico acerca de las industrias inferopaleolíticas de la cuenca del Duero. Para eso, se necesitan excavaciones, que no hay, pues, excepto las de Atapuerca y poco más, investigadores acreditados tienen que estar en paro, a la vez que los yacimientos en terraza se siguen destruyendo (explotación de graveras, aterrazamientos para regadíos, etc.) para desgracia de todos y sin sacarles el debido provecho científico. Con las excavaciones que hay hasta ahora, nadie está en condiciones de demostrar cómo y cuándo nos llega el Achelense, y cómo y cuándo desaparece, y si la evolución que hay en él (constatada en el yacimiento de "El Basalito") responde a una cronía real o es sólo de tipo tecnotipológico. Todo lo más, se apuntan hipótesis, pero todavía nada definitivo.

\section{BIBLIOGRAFÍA}

AGUIRRE, E.; CARBONELL, E, y BERMÚDEZ DE CASTRO, J. M. (eds.) (1987): El hombre fósil de Ibeas y el Pleistoceno de la sierra de Atapuerca. Junta de Castilla y León.

ARNÁIZ, M. A. (1995): "El Paleolítico Inferior en el tramo medio-alto del río Pisuerga: situación actual de la investigación”, III congreso de Historia de Palencia, tomo I: Prehistoria, Arqueología e Historia antigua: 11-33.

BENITO DEL REY, L. (1978): "El yacimiento achelense de «El Basalito» (Castraz de Yeltes, Salamanca). Segunda parte: estudio de la industria de piedra", Zephyrus XXVIII-XXIX: 67-92.

- (1990): "El Paleolítico inferior en la provincia de Zamora", I Congreso de Historia de Zamora, tomo 2: Prehistoria y mundo antiguo: 11-52. Zamora, 14 al 18 de marzo de 1988.

BENITO DEL REY, L y BENITO ÁLVAREZ, J. M. (1992): "La Salamanca paleolítica”, I Congreso de Historia de Salamanca, 1989. Tomo I: 117-169. Diputación de Salamanca.

_ (1998): Métodos y materias instrumentales en Prehistoria y Arqueología (la Edad de la Piedra tallada más antigua). Tres volúmenes. Ediciones Cervantes. Salamanca.

BERMÚDEZ DE CASTRO, J.M.; ARSUAGA, J.L.; CARBONELL, E. y RODRÍGUEZ, J. (Eds.) (1999): Atapuerca. Nuestros antecesores. CSIC-J. de Castilla y León.

CASTELLANOS, P. (1986): El Paleolítico Inferior en la submeseta norte -León-. Diputación de León.

CARBONELL, E.; GIRALT, S. et al. (1995): "El conjunto lito-técnico de la sierra de Atapuerca en el marco del Pleistoceno Medio europeo", Evolución humana en Europa y los yacimientos de la sierra de Atapuerca: 445-555. Congreso de Medina del Campo, 1992. Junta de Castilla y León.

DÍAZDEL OLMO, F.; VALLESPÍ, E. y ÁLVAREZ, G. (1987): “Trabajos de 1985 sobre formaciones cuaternarias y conexiones paleolíticas en el bajo Guadalquivir, provincia de Sevilla", Anuario arqueológico de Andalucía 1985, II actividades sistemáticas: 13-16.

13. Es lo que ha pasado con "El Basalito", yacimiento en el que, superficialmente, se recogieron pocas lascas y demás útiles sobre lasca, en relación y proporción con la macroindustria o industria pesada (bifaces, hendidores y cantos tallados) lo que es normal en una recogida superficial de materiales de una terraza, y es algo tan elemental, que conoce hasta el más torpe de los estudiantes de primero de Prehistoria. Por ello, sorprende más que F. Díez Martín diga , tendenciosamente, que la muestra recogida en "El Basalito" es "profundamente parcial y aleatoria" (Díez Martín 1999: 63, nota 4), porque contiene pocas lascas y útiles sobre lasca en proporción con la macroindustria, limitaciones reconocidas en la propia publicación (Benito del Rey 1978: 73 y 91) y que no es un error, sino algo normal en la recogida de muestras, a ras de suelo, de un yacimiento en terraza fluvial.

Por otro lado, en la excavación realizada por nosotros, en 1987, en el propio yacimiento de "El Basalito", la proporción de lascas exhumadas fue muchísimo mayor con relación a la industria más pesada (bifaces, hendidores, núcleos, útiles sobre lasca, etc.), lo que es también normal en una excavación. 
DÍAZ DEL OLMO, F.; VALLESPÍ, E. y BAENA, R. (1993): “Cuaternario y secuencia paleolítica en las terrazas del medio y bajo Guadalquivir: aluvionamientos, coluviones, suelos y paleosuelos", Investigaciones arqueológicas en Andalucía, 1985-1992, VI proyectos.

DÍEZ MARTÍN, F. (1999): "Sobre el cambio tecnológico: el paradigma gradualista y la transición entre el Paleolítico inferior y medio", Zephyrus LII: 53-78.

JIMÉNEZ E. y GARCÍA, J. M. (1981): Mapa geológico de España, 1:50 000, hoja 398, “Castronuño”, IGME, Madrid.

PÉREZ-GONZÁLEZ, A. (1982): "El cuaternario de la región central de la cuenca del Duero y sus principales rasgos geomorfológicos", $1^{a}$ reunión regional sobre la Geología de la Cuenca del Duero (Salamanca, 1979): 717-740. IGME, Madrid.

MARTÍN BENITO, J. I. (2000): El Achelense en la cuenca media occidental del Duero. C. E. B. «Ledo del Pozo», I. E. Z. «Florian de Ocampo» (CECEL-CSIC).

MARTÍN HERRERO, D. y otros (1990): Mapa geológico de España, 1:50000, hoja 525, “Ciudad Rodrigo", IGME, Madrid.

ROJO, A. y MORENO, M. A. (1979): "Industrias del Paleolítico inferior en las terrazas del río Pisuerga (Valladolid)", BSAA XLV: 148-157.

SANTONJA, M. y PÉREZ-GONZÁLEZ, A. (1984): Las industrias de la Maya I en su ámbito regional. E. A. E. 135. Ministerio de Cultura, Madrid.

SANTONJA, M. (1991): "Comentarios generales sobre la dinámica del poblamiento antiguo en la provincia de Salamanca", Del Paleolítico a la Historia: 13-31. Museo de Salamanca y Junta de Castilla y León.

SANTONJA, M. (1992): "Los últimos diez años en la investigación del Paleolítico Inferior de la cuenca del Duero", Veleia 8-9: 7-41.

VALLESPÍ, E. J.; DÍAZ DEL OLMO, F.; ÁLVAREZ, G. y VALLESPÍ, E. (1988): “Secuencia paleolítica del bajo Guadalquivir", Revista de Arqueología 82: 9-17. 